\title{
Computer Supported Collaborative Learning for Developing Higher Order Thinking Skill in ELT
}

\author{
Ambika Prasad Poudel \\ Tribhuvan University, Dhankuta Multiple Campus, Nepal
}

\begin{abstract}
The practice of integrating pedagogical approaches using multimedia technologies has become one of the common interests in education in recent years. The technology-based approaches such as computer-supported collaborative learning (CSCL) and electronic literacy approach (ELA) are spreading widely in English language teaching (ELT) at present. The research reported in this article studied the characteristics of CSCL tasks in the context of ELT in higher secondary school education in Nepal. Nonparticipant observation of the CSCL tasks assigned to the students in the English class in two different schools, and semi-structured interviews with the students were used as research tools. It was found in the study that the CSCL tasks were useful for enhancing some cognitive skills of the students, though many of the CSCL tasks assigned were more exam-oriented and the teachers gave limited attention to enhance students' higher order thinking skills. This shows that the integration of technology-aided new modes of learning do not in themselves foster higher-order learning; that goal requires deliberate curricular and pedagogical efforts of educators. This study offers new insights for the teachers, students, educators and all others who are interested in technology-based education.
\end{abstract}

Keywords: Technology-based education, collaboration, constructivism, scaffolding, cognitive skills, HOTS 
The technology-based education integrating digital media in teaching and learning has become one of the common interests in the practice of English language teaching (ELT) at present. It is because technology-mediated education has possibilities of providing several opportunities in media-based instruction in general, and in English language teaching and learning in particular (Pim, 2013; Rank, Warren, \& Millum 2011). Among various pedagogical approaches in technology-based education, CSCL can enable the learners for cross-fertilization of knowledge by creating environment for discussing and negotiating ideas, and for sharing learning resources with different possibilities of improving their quality of cognitive skills (Stahl, Koschmann, \& Suthers 2006). It is an emerging branch of learning sciences that concerns with learning together by means of social interaction in technology supported environment.

CSCL includes two broad concepts- 'computer support' which refers to the integration of technologies such as web 2.0; and 'collaborative learning' which indicates learning together for co-construction of knowledge through mutual engagement. Historically, CSCL arose as a reaction to the pedagogy of software that forced individual learning (Stahl, Koschmann, \& Suthers, 2006). In fact, collaborative learning involves individual learning too; however, the unit of analysis in collaborative learning is the group, not an individual. Collaborative learning is different from co-operative learning in which 'partners split the work, solve sub-tasks individually, and then assemble the partial results into the final output'; whereas in collaboration 'partners do the work together to solve the problem' (Dillenbourg, 1999, p. 8). Thus, working together in a group to learn with support of technological tools is the main essence of CSCL

According to Phielix, Prins, Kirschner, Erkens and Jaspers (2011), both cognitive process such as reasoning, critical thinking, problem-solving; and social process such as developing social relationships, and feeling of group trust are the keys to successful collaborative learning. The educational value of CSCL is that it is useful to create an environment that enhances not only the language skills but also cognitive skills and social skills of the learners through carefully designed CSCL tasks Ada (2009). The social interaction and collaboration establish a learning community, which creates possibilities for fostering cognitive skills including both lower order thinking skills (LOTS) and higher order thinking skills (HOTS) through the process of co-construction of knowledge.

According to Persico and Pozzi (2011, p. 3), tasks, team and timethe three Ts' - are the characterizing elements to structure the CSCL process. Thus, the tasks that the students are asked to carry out are one of the important components in CSCL. Persico and Pozzi (2011) stress that there should be a careful tuning of tasks, teams and time for smooth going of CSCL process. Likewise, Weinberger (2011) views that the design of the learning tasks and the scaffolding of the teachers can give the students many 
benefits for problem-solving in CSCL activities. For appropriate and effective integration of technology-based approaches in education, Koehler, Mishra and Cain (2013) stress the crucial role of technological pedagogical and content knowledge (TPACK) of the teacher,

English language teachers can take different advantages of multimedia technologies for engaging the learners in negotiating meanings and sharing cognitive resources relevant to problem-solving tasks to enhance the students' cognitive skills in the CSCL environment (Liu, 2012; Phielix et al., 2011). However, technology integration in school education in developing country Nepal has recently been introduced (MOE, 2013); and many of the schools are struggling with the challenges such as information and communication technology (ICT) infrastructure development, instructional materials and pedagogical training to the teachers (Giri, 2010; UNESCO, 2015). Some of the schools that are relatively stronger in infrastructure management trying their best to integrate ICTs and use the approaches such as computer-mediated communication (CMC) and CSCL in ELT and in teaching other subjects as well. In this regard, the CSCL approach practiced in school education in Nepal might have its own special characteristics. Therefore, it is beneficial to study and explore these characteristics of the integration of CSCL approach.

One of the very essential components in CSCL is the integration of ICTs that have potentialities of making learning activities faster, easier, and more enjoying. However, technological tools are like a double-edged sword (Khechine \& Lakhal, 2018), and their benefits and usefulness in a pedagogical approach depend on the context where and how they have been used. Therefore, success of CSCL approach is also greatly influenced by the factors such as the way the technological tools have been integrated and the tasks designed to be conducted. In this regard, several research studies have been carried out to explore the issues such as technological tools for CSCL, social aspects in CSCL, pedagogical challenges in CSCL, team effectiveness and benefits of CSCL, and so on. However, the studies related to CSCL tasks-one of the key elements in CSCL process-, and particularly, the characteristics of the tasks in CSCL activities that play important role in the development of cognitive skills of the students are still quite a few. Moreover, as the integration of technology-based approach in Nepalese school education is at its learning phase (MOE, 2013), and the new approaches and platforms of teaching and learning such as CSCL, blogs, Moodle etc. have been recently introduced in ELT; it is essential and worthwhile to study and explore the characteristics and efficiency of such new approaches in the context of their use in Nepalese educational institutions. Taking all these into consideration, the research questions I have raised in this study were: 
(i) What are the characteristics of the CSCL tasks designed by the teachers to be conducted by the students in the context of ELT in the higher secondary school education in Nepal?

(ii) What cognitive process dimensions do the CSCL tasks contain?

This study investigates the characteristics of CSCL tasks that play an important role in developing cognitive skills of the students learning English at higher secondary school in Nepal. The study has been expected to add at least a few empirical findings in the field of research in CSCL and ELT. Importantly, the study gives some insights to the teachers, students, and educators concerned with English language teaching and learning to improve the quality of school education. It has also been expected that the study will be a useful document to anyone who are interested in technology integration in English education.

\section{Theoretical Framework}

The theoretical framework that guides to understand and explore the integration of CSCL activities in ELT in this study is social constructivism. Social constructivism is one of the several schools of thought under cognitivist constructivism (Dakich, 2014). According to Jonassen (1999), constructivist theorists view that learners construct and co-construct knowledge both individually and socially through their interactions with the world when they are engaged in active, interactive and collaborative learning activities. Social constructivism is a theory of knowledge which assumes that meaning and understanding are developed through active interaction and co-ordination in social activities (Leeds-Hurwitz, 2009). In the social constructivist learning environment, the learners are surrounded by the tools and resources that provide opportunities for learning, interaction and collaboration, where the learners' activities are initiated by several problem-based tasks (Jonassen, 1999). ICTs in CSCL can act as a catalyst to bring a change in education because they have the capacity to shape collaborative, interactive, constructivist, and constructionist approach to learning (Drigas, Kokkalia, \& Lytras, 2015)

One of the pioneers of social constructivism, L. Vygotsky (1978) views that as knowledge is constructed socially and culturally, and then is internalized and used by the individuals; to make sense and construct knowledge, the learners need to relate themselves in social circumstances. According to Vygotsky, the learners' actual development level related to problem-solving can be extended through social interaction and collaboration. This enables the learners to move into a new zone of cognitive maturity called 'zone of proximal development'(ZPD), which to Vygotsky is "the distance between the actual development level as determined through problem-solving through adult guidance or in collaboration with more capable peers" (p. 86). The web 2.0 technologies in this information age create lots of opportunities providing valuable tools and 
learning resources for scaffolding and developing such cognitive maturity and HOTS in CSCL environments (Dakich, 2014; Jonassen, 1999; SirajBlatchford \& Siraj-Blatchford, 2006). The theory of constructivism is highly relevant for enhancing knowledge construction and cognitive development of the learners in this digital age of the $21^{\text {st }}$ century world.

\section{Methodology}

Based on social constructivism as the theoretical lens, this study followed the qualitative research approach which emphasizes the exploration of meaning and conclusion by means of observation and interpretation (Creswell, 2014). For the purpose of data collection, two higher secondary schools/colleges that were running ICT-based instruction as their teaching-learning strategy from the Kathmandu valley, Nepal were selected by means of purposeful intensity sampling methods (Patton, 2002, p.234). According to Patton (2002), purposeful sampling enables the researchers to represent the phenomenon of the study more strongly. The college administration and the teachers were requested for their permission to conduct a non-participant observation of the compulsory English class of grade eleven at both higher secondary schools for 13 weeks (from the opening of the session to the first term examination) to study the CSCL tasks and activities of the teachers and the students. The two classes (one class at each college) observed were assigned pseudonyms as 'class A' and 'class B' for confidentiality according to research ethics (Saunders, Kitzinger \& Kitzinger, 2015) in the data analysis process.

Non-participant observation is a relatively more unobtrusive method of primary data collection about some aspects of social phenomena without directly interacting with the participants and without affecting their spontaneity in natural settings. This method helps the researcher minimize the 'reactive effects' while observing individual behavior or process (Bryman, 2004, p. 175). In this study, the tasks that were designed by the teachers to be carried out by the students as the CSCL activities were observed and noted down in the observation diary during the 13 weeks' period of information/data collection. The design of the tasks and the students' performance on the tasks were carefully watched and field notes were taken to understand their characteristics. In addition, information about the characteristics of the tasks and their experiences of using CSCL approach were also taken from the class teachers through informal discussions. The tasks were classified in terms of their nature to develop cognitive skills of the students based on 'the revision of Bloom's taxonomy' by D. R. Krathwohl (2002), which is the review of 'the taxonomy of educational objectives and classification of educational outcomes' (Bloom, Engelhart, Furst, Hill \& Krathwohl, 1956). Krathwohl categorizes 'the cognitive process dimensions' into six types: remembering (e.g. recalling), 
understanding (e.g. summarizing), applying (e.g. implementing), analyzing (e.g. differentiating), evaluating (e. g. critiquing), and creating (e. g. producing); in a hierarchy from less complex to high complex skill; and then, he classifies these six types into two: the first three which are relatively less complex, are said to be lower order thinking skills (LOTS), and the last three which are comparatively more complex, are said to be higher order thinking skills (HOTS). In this study too, the tasks given to the students were observed and categorized into LOTS and HOTS following Krathwohl. The findings were shown in tables and charts; and were analyzed and interpreted using descriptive statistics.

Besides non-participant observation, three students from each class were selected using probability random sampling methods for the purpose of semi-structured interviews. Random sampling is one of the most rigorous forms of sampling, which helps the researcher to make generalizations in the population (Creswell, 2012). It enables to control biasness likely to occur, and thus, to increase reliability in the study. Semi-structured interviews, according to Creswell (2012) are the most commonly used tools in qualitative research that allows the participants to voice and describe their experiences in more detail. For interviewing in this study, some open-ended questions were prepared to understand the students' in-depth experiences of CSCL tasks and activities. The three students selected from class A were assigned pseudo names A1, A2, and A3; and the students from class B were assigned pseudo names B1, B2, and B3 for establishing confidentiality. The information collected through the semi-structured interviews were analyzed and interpreted thematically and conclusions were drawn based on the interview findings and the field- experiences of the researcher.

\section{Results and Discussion}

In this section, the information and data collected through observation and semi-structured interviews have been presented in thematic narrations, and in tables and charts. Particularly, the relevant issues of the study- characteristics of the CSCL tasks, and the cognitive process dimensions in the CSCL tasks- have been discussed and analyzed. The findings have been explained and interpreted in the sub-headings to come for more clear understanding of the main issues.

\section{Characteristics of CSCL tasks and activities}

It was found in the observation that there was integration of CSCL tasks to be conducted by the students in both of the classes in their ELT practice. On average, the students were given collaborative tasks once a week to be carried out as a group work. The teachers were the facilitators in conducting the tasks. Most often, the teachers announced the tasks in the class, they divided four to six students into a group, and informed the students of their group membership. The group leaders were selected 
sometimes by the teacher, and sometimes by the students themselves in class A while in class B it was the teacher who chose the group leaders. Likewise, the task submission deadline, and the day of group presentation was also notified by the teachers. Some of the important common characteristics of the CSCL tasks and activities of the observed classes have been discussed in the following points:

(i) Tasks copied from the text-book: It was found that most of the tasks were the exact copy of the questions given in the exercise and activities in the prescribed textbooks (see Table 1 and Table 2). Little attention was given to modify the questions of the textbooks to be carried out as the CSCL tasks. The students were found to be satisfied with such tasks. One of the participants, 'B2', shared his experiences,

The tasks are useful not only to enhance our language skills and cognitive skills, but it is also that they are the possible questions for our examinations. If we work on the tasks given, there is a chance of securing good marks in the tests and examinations and achieving the goals of the curriculum.

It is not completely inappropriate to design the CSCL tasks, making them similar to the exercises of the textbooks. As there is usually a good co-relation between the textbook and the curriculum, such tasks might be useful to help the students achieve the objectives determined by the curriculum. The findings in this study go in the line of Persico and Pozzi (2011) who viewed that tasks should be based on the learning objectives and the contents to be addressed.

The types of the tasks copied from the textbook seem to engage the students in collaboration and improve their knowledge in some ways. In the informal discussion, the teachers opined that with such tasks, they intended to facilitate the students' cognitive skills; and at the same time, they wanted to help the students to be prepared for the examinations because those were the most possibly repeated questions in the examinations. The teachers were not wrong in their logic. However, it indicates the exam-oriented mentality of the teacher rather than giving emphasis to improving creativity of the students. Moreover, with such text-book tasks, there is equally a greater possibility for the students to copy the solutions of such tasks from the guidebooks available in the market, which increases the possibility of hindering the students' creativity skills. Therefore, in the CSCL approach, the tasks need to be carefully designed so as to enhance the students' problem solving and creativity skills. This requires the teachers to have more skills and experiences to link the textbook contexts with their practical life while designing tasks in CSCL. As suggested in Koehler, Mishra and Cain (2013), TPACK of the teacher is significantly important in the technology-based approach including CSCL to design teaching-learning tasks. 
(ii) Scaffoldings: It was found in this study that the students expected more scaffoldings and support from the teacher in their collaborative activities and the teachers provided the students with frequent guidelines and a lot of scaffoldings in carrying out the tasks in the CSCL activities. The teachers encouraged the students to actively participate in conducting the tasks, they instructed in planning the tasks and provided learning resources to facilitate the students' activities. It was also that the students could take advantages of the support from both the teachers and their intelligent peers in solving the tasks. Participant A1 reacted,

Our teacher gives us useful hints while carrying out the CSCL tasks. He provides us with relevant learning materials and website links to consult. Besides, we can get lots of help from our group members. We can observe how our peers work and share our feelings and difficulties more frankly with them.

In the informal discussion, the teachers shared their experiences that they provided the students lots of scaffoldings because it was the first term of the session and the students were in the initial phase of the session, where more guidance was required to support and to form the students' habit in carrying out collaborative learning activities. However, according to Dillenbourg and Jerman (2007), over scaffoldings or guidance might hinder the students' creativity and self-regulation. On the other hand, Liu and Tsai (2008) view that an excess of freedom might not engage all the students in productive interaction in CSCL tasks. As Persico and Pozzi (2011) opine, it would have been better if the teachers could maintain a balance between over scaffoldings and over freedom. The teachers need more experiences and pedagogical training to develop such skills of applying CSCL approach into the classroom.

(iii) Participation: Active participation of the group members is one of the most requiring aspects of CSCL. In general, there was considerably good participation of the students in both the classes. In the observation, many of the students were interested in doing the tasks given, however, it was found that some of the students rather lacked their motivation despite the teacher's encouragement. In the interview, A 3 shared,

In some of the groups, some of the friends are rather passive.

They do not labor, but depend on other friends, and just act as

if they are showing their participation.

One of the main characteristics of CSCL is that it creates several opportunities for interaction and collaboration, but the teachers need to be more careful to engage all the learners in the activities given (Drigas, Kokkalia, \& Lytras, 2015). The teacher might need to treat the students individually if it required. He needs to move around the 
groups in the class, and need to follow both synchronously and asynchronously giving feedback. This requires appropriate size of the class, and the teachers to be more active and experienced. In the discussion, the teachers shared that the size of the class and overload to the teachers were some of the important challenging and problematic factors for them to provide frequent feedback to the students. However, it is the teacher, who can play an important role for creating an environment where the students participate actively and work collaboratively. This helps enhance cross-fertilization of knowledge discussed in Stahl, Koschmann, and Suthers (2006) in CSCL approach.

(iv) Strategy: The strategies of the teacher play significant role in group mobilization and active participation in the CSCL activities. It was observed in the study that the teachers' design of the CSCL tasks making them similar to the textbook exercise, was also one of the useful strategies for motivating the students in both the classes. Likewise, the teachers frequently modified the structure of team members that could add not only newness and curiosity among the students, but also that the students experienced the varieties in socialization and other social aspects. Likewise, the strategies like bringing variations in the role of team-leader and making the name of the group presenter unknown until the time of presentation were useful for increasing the students' active participation. Similarly, the teacher in class A used other strategies such as 'first submission award' and 'winner prize' to motivate and encourage the students. In the interview, one of the participants, 'B1' said,

We do not know who will present our preparation until the time of presentation. This makes everyone sincere and well prepared in carrying out the tasks given.

As Weinberger (2011) discussed, the pedagogical skills of the teachers to design the strategy of teaching, and their balanced scaffoldings are very important in CSCL to make it more effective. In this study, the strategy of making the CSCL tasks similar to textbook exercise mainly targeted tests and examinations apart from the development of some cognitive skills of the students at the same time. Likewise, the strategies such as 'first submission award' and 'winner prize' not only encouraged the students to complete the tasks in time but also aroused a sense of competition among the groups. In this way, the teachers in this study were found to be careful to consider the factors such as the nature of the team and availability of time while designing the tasks though they were less attentive towards cognitive skills development of the students. Several factors such as technological-pedagogical knowledge of the teachers, level of students' knowledge and skills, classroom environment, resource 
availability to the students, might have influenced in designing the strategy and CSCL tasks. In the discussion, the teachers shared their experiences that they were not confident about the strategies appropriate to CSCL approach because they did not have got any opportunity to take part in pedagogical training or workshops to the teachers.

\section{CSCL tasks and cognitive skill development}

The participants shared their experiences that the tasks designed by the teachers increased the students' participation in the activities of English language skills development such as listening, speaking, reading and writing. They reported that the CSCL tasks helped facilitate their communicative power, sharing learning resources, and enhance their skills of taking part in discussion and in meaning negotiation. Besides, the analysis of the information in the observation showed that the tasks were also useful to enhance their cognitive skills to some extent.

It was found in the observation that most of the CSCL tasks were announced in the classroom by the teachers while some of them were sent through email. The teachers encouraged the students towards collaborative group work with such tasks though they did not seem to give more emphasis for the development of HOTs of the students. The CSCL tasks, cognitive process dimension of the task and the type of cognitive skill that the tasks facilitated the students' cognitive development in class A and class B in this study have been presented in Table- 1 and in Table- 2 respectively.

\section{Table 1}

\section{CSCL tasks and the cognitive skills in class-A}

S.

N. CSCL Tasks

\section{Category of cognitive domain}

Type of cognitive skill that the task facilitated

Define dictionary and write any three advantages of a dictionary.

remember LOTS

2 Describe any four situations of the use of present continuous tense.

understan

LOTS

Write a short description of your daily

3 routine and compare it with one of your friend's routine.

Write an account of some of the most important events in your country's history

analyze HOTS

understan

d

LOTS 
List the advantages and disadvantages of a small and a large family

remember LOTS

6 Write your arguments against deforestation in a few paragraphs.

7 Write a short description of your classroom

8 Write a few paragraphs comparing village life and city life.

9 Explain the effect of world war in reference to 'Look at a tea cup'

Explain the paradox "child is the father of man'

Compare 'The loving mother' with 'The house call'.

12 Why is unchopping a tree impossible?

Write a description on how Halloween is celebrated

14 Construct a story using the hints given What are the possible ways of giving 15 advice? Write an advisory paragraph including advice

evaluate HOTS

understan LOTS

analyze HOTS

understan LOTS

d

understan LOTS

d

understan

d

LOTS

evaluate HOTS

understan

d

LOTS

create

HOTS

apply LOTS

Table 1 shows the information collected during the period of class observation in class A. It reveals the tasks assigned to the students, and their characteristics. During the observation period, altogether 15 tasks were assigned to the students. It was found that most of the tasks were copied from the lessons and activities given in the text-books prescribed. The Table shows that though the tasks covered all the cognitive domains, many of the tasks were related to 'understand', the second complex cognitive process in the hierarchy of the cognitive process dimension. The data reveal that majority of the tasks, 10 out of 15 tasks (i. e., 66.6\%) were less complex; classified into LOTS while five of them (i. e., 33.3\%) were relatively more complex categorized into HOTS.

It was found that the tasks assigned covered different cognitive dimensions. Out of 15 tasks observed, seven tasks (46.6\%) were related to the cognitive dimension 'understand' categorized into LOTS (see Figure 1). Likewise, there were two tasks associated to the dimensions 'remember', and one task was associated with 'apply'. Similarly, the dimensions 'analyze', and 'evaluation' categorized into HOTS contained two tasks 
each., while the highest complexity in the hierarchy of cognitive process 'create' contained one task only.

A close observation of the information collected shows that most of the CSCL tasks were the same as the exercises and the activities of the textbooks. The tasks seem to be useful to develop the learners' cognitive skills to some extent. However, such tasks increase the possibility of copying the solution form the guidebooks by the students instead of using their creativity. It shows that little attention was paid to engage the students in the development of their HOTS. Even within the category of LOTS, it seemed that more focus was given to the simple level skills in the hierarchy of the complexity of the cognitive skills. There was only one activity related to relatively more complex skill 'apply'. The same trend was found among the tasks related to HOTS provided to the students. Most of the activities and the tasks were related to relatively low-level skills in the hierarchy of their complexity. There was only one task related to the most complex cognitive skill 'create'. Additionally, none of the tasks was teacher's own original that could relate the students' real-life situation with the context of the text.

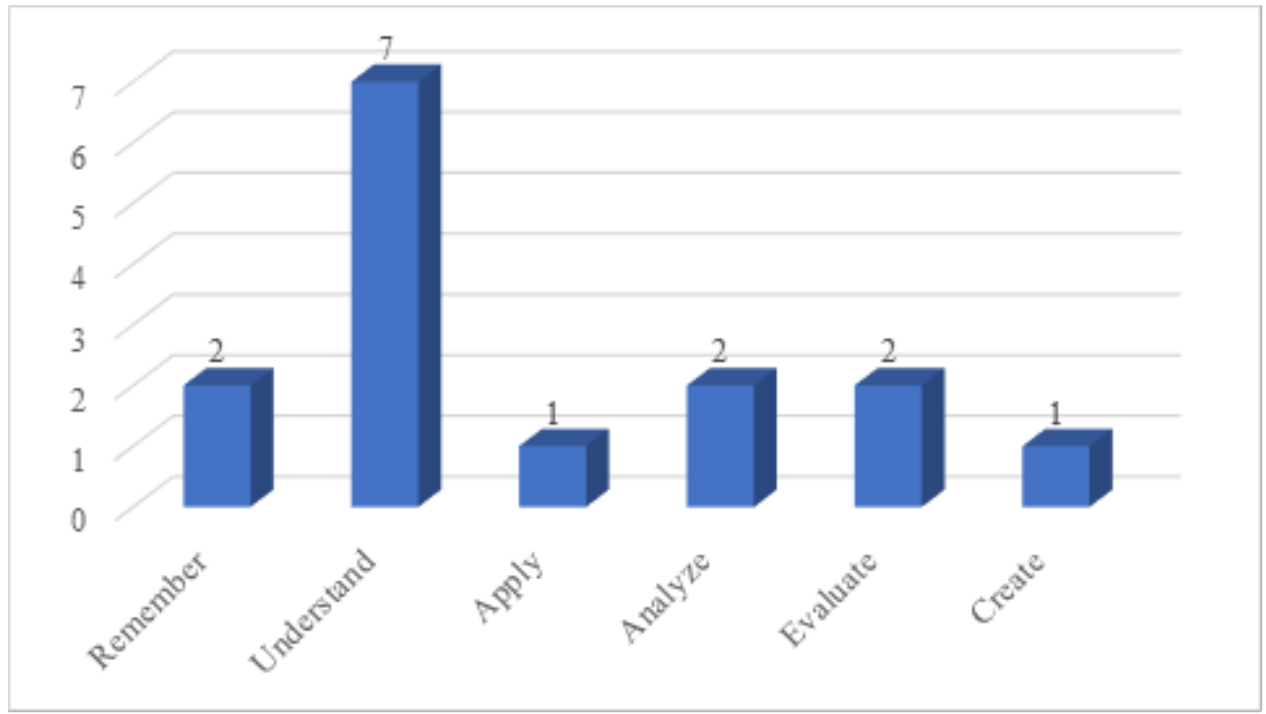

Figure 1: CSCL tasks and their cognitive process dimensions in class-A

Table 2 presents a summary of the data collected from class B. It shows the CSCL tasks and their characteristics - the cognitive process dimension the tasks supported, and the type of cognitive skill - in class B. During the observation period, there were 12 tasks assigned to the students. The data show that three out of 12 tasks (i. e., 25\%) were relatively more complex categorized into HOTS. Majority of the tasks, nine out of 12 tasks (i. e., 75\%) were less complex; classified into LOTS. 
S.

N. CSCL Tasks

\begin{tabular}{ll} 
Category & $\begin{array}{l}\text { Type of } \\
\text { cognitive }\end{array}$ \\
of & $\begin{array}{l}\text { skill that } \\
\text { cognitive } \\
\text { domain the task } \\
\text { facilitated }\end{array}$ \\
\hline
\end{tabular}

remember LOTS

create HOTS

understand LOTS

remember LOTS

evaluate HOTS

understand LOTS

apply LOTS

understand LOTS

understand LOTS

evaluate HOTS

understand LOTS

apply $\quad$ LOTS

12 your friend using the expressions for asking for permission

Figure 2 shows the coverage of the cognitive skills dimension with the tasks assigned in class-B. It reveals that the cognitive process dimensions 'understand', the second category of the cognitive process dimension belonging to LOTS contains five tasks, almost half of the total tasks. Likewise, other dimensions ' remember' and 'apply' contained two tasks each. On the other hand, the dimensions belonging to HOTS 'evaluate' contained two tasks, while 'analyze' contained no task at all. The highest complexity in the hierarchy of cognitive process dimension 'create' contained one task. 


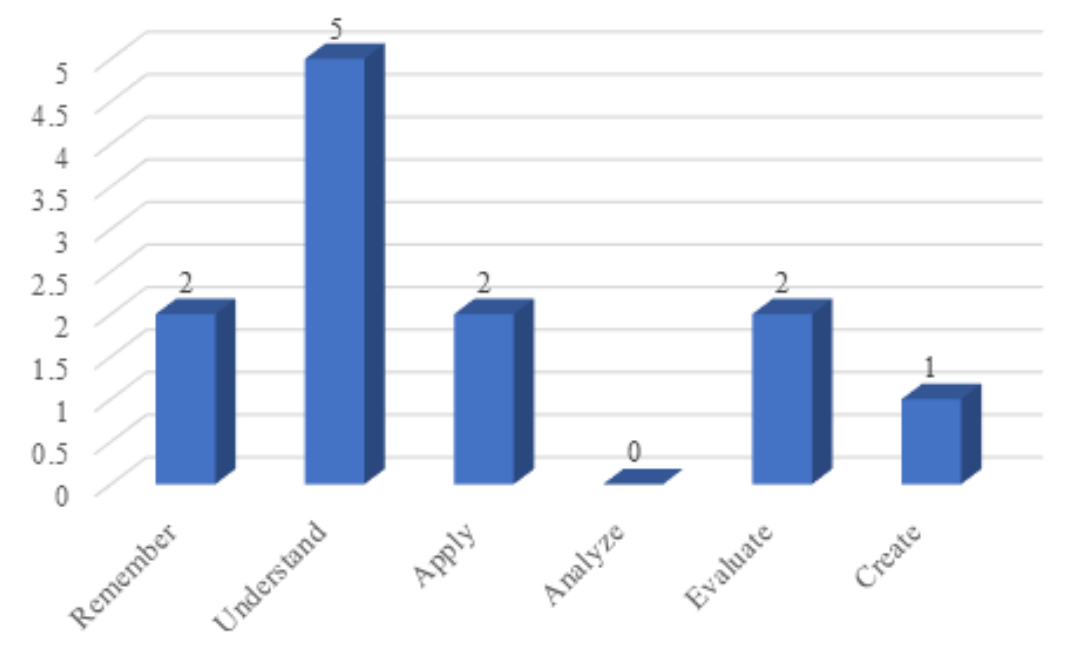

Figure 2: CSCL tasks and their categories of cognitive process dimension in class-B

In the observation it was found that both face to face classroom mode and online mode were used to give the tasks to the students and attempts were made to cover most of the cognitive domains. The information collected reveal that similar to class A, the tasks were copied from the activity section of the textbooks in class B too. Little attention was given to modify the questions so as to connect the tasks with the students' real-life situation. The tasks were useful to develop many of the cognitive skills in some ways. However, it seemed that emphasize was given to LOTS rather than to HOTS. Within these LOTs and HOTs, many of the tasks were associated with lower level rather than higher level skills in the hierarchy of their complexity.

The findings show that most of the tasks were not beyond the level of difficulty of the average students of grade eleven in context of Nepalese school education because the tasks were based on the authentically prescribed textbooks in both classes. It was found that the frequency and the number of the tasks given to the students was relatively higher in class A than in class B. The teacher in class A gave 15 CSCL tasks while the teacher in class B gave 12 CSCL tasks during the period of 13 weeks' observation. It seemed that the frequency of the CSCL tasks given to the students was once a week in average, and it was not adequate enough to engage the students in cognitive skills development. One of the teachers in the informal discussion viewed that such low frequency of the tasks was due to the length of the syllabus that he did not have enough time to engage his students in more collaborative group works.

CSCL approach creates a lot of potentialities for enhancing cognitive maturity of the students (Dakich, 2014). However, it was found in the study that the number of the tasks associated with facilitating HOTS was 
quite smaller in comparison to the tasks associated with the development of LOTS in both classes. As a matter of fact, LOTS and HOTS are interconnected, and HOTS cannot be enhanced separately from LOTS. However, the knowledge-based society of the twenty-first century requires a change in educational paradigm giving main focus to the development of HOTS (PPRC, 2010). Tanujaya, Mumu, \& Margono (2017) claim that the students who practice HOTS tend to be more successful because the students with HOTS are more capable to learn, perform, prepare for challenges and solving problems, and in critical and creative thinking. In this study, the teachers in both classes seemed to give little attention to promote HOTS of the students in designing the tasks. There were several responsible factors behind this. In the informal discussion, one of the teachers stated that it was the first term of the academic year, and the teacher was making the students familiar and motivated towards the tasks involving them in relatively more simple activities. Another teacher shared his experiences that many of his students in the class were not capable to perform more complex tasks and that the teachers needed to use relatively simple tasks. He expressed that a considerable number of the students in English class do not have adequate previous level knowledge mainly due to the evaluation system which allows to upgrade students though they fail in one or two subjects among total subjects of their curriculum. More importantly, the teachers also accepted that they were less confident as they were not trained, and they had insufficient technological and pedagogical knowledge so as to design more appropriate CSCL tasks. As Koehler, Mishra and Cain (2013) stressed the significant of TPACK for productive utilization of technology-mediated approaches for adding quality in teaching and learning; concerned people need to give more attention to this causing factor.

\section{Conclusion}

CSCL is one of the recently emerged pedagogical approaches under the constructivist paradigm that can enable the learners for co-construction of knowledge with the support of CMC environments. The designing of CSCL tasks is one of the essential components in CSCL approach for helping the students promote their cognitive skills such as LOTS and HOTS. However, the CSCL tasks and activities in ELT class in the school education in Nepal are more exam oriented, and they are not adequate in number. Likewise, the class sizes are not well manageable to conduct collaborative group tasks and that the students demand over scaffoldings from the teachers. Moreover, most of the CSCL tasks are found to be of LOTS promoting category, and little attention has been given by the teachers to promote HOTS of the students. The CSCL activities have also been influenced by some provisions existed in syllabus and evaluation system. 
Therefore, for successful integration of CSCL approach, the teachers and students need to abandon their exam-oriented mentality. Likewise, the teachers need to be more careful to maintain a balanced scaffolding, and give more attention to promote self-regulation and HOTS of the students. Additionally, the government and educational administration need to formulate some plans and policies to manage class size, and to bring improvement in curriculum and syllabus and in the system of evaluation. More importantly, among several pre-requisites for the success of CSCL approach, the designing of appropriate tasks is significantly important, which requires a good TPACK of the teacher because the quality of the CSCL tasks is greatly influenced by their knowledge and skills. Therefore, pedagogical training and workshops about the use of new technological tools and pedagogical approaches are needed to be organized more frequently. This can also contribute to update and upgrade the teachers, to improve their teaching profession, and to advance the quality of education.

\section{References}

Ada W. W. M., (2009). Computer Supported Collaborative Learning and Higher Order Thinking Skills: A Case Study of Textile Studies. Interdisciplinary Journal of E-Learning and Learning Objects, Vol 5, pp. 145-167.

Bloom, B. S., Engelhart, M. D., Furst, E. J., Hill, W. H., \& Krathwohl, D. R. (1956). Taxonomy of educational objectives: The classification of educational goals. London: Longman

Bryman, A. (2004) Social Research Methods. Oxford: OUP.

Creswell, J. W. (2012). Educational Research: Planning, conducting, and evaluating quantitative and qualitative research. Boston: Pearson.

Creswell, J. W. (2014). Research design: Qualitative, quantitative, and mixed methods design. London: Sage.

Dakich, E. (2014). Theoretical and epistemological foundations of integrating digital technologies in education in the second half of the $20^{\text {th }}$ century. In A. Tatnall and B. Davey (Eds), History of computers in education, IFIP, AICT, Vol 424, pp. 150-163. Heidelberg: Springer

Dillenbourg, P. (1999). What do you mean by "collaborative learning"? In P. Dillenbourg (Ed.), Collaborative learning: Cognitive and computational approaches (pp. 1-16). Amsterdam, NL: Pergamon, Elsevier Science.

Dillenbourg, P. \& Jermann, P. (2007). Designing interactive scripts. In F. Fischer, I. Kollar, H. Mandl, \& J. Haake (Eds.) Scripting computer supported collaborative learning: Cognitive, computational and educational perspectives (pp. 276-301). New York: Springer

Drigas, A., Kokkalia, G., Lytras, M. D. (2015). ICT and collaborative colearning in preschool children who face memory difficulties. 
Computers in Human Behavior 51(PB), 645-651. DOI: $10.1016 /$ j.chb.2015.01.019

Giri, R. A. (2010). English language teachers' resource center: A model for developing contexts. Journal of NELTA, 15 (1-2), pp. 64-76.

Jonassen, D. (1999). Designing Constructivist Learning Environments. In C. M. Reigeluth (ed.), Instructional Design Theories and Models, Volume II, USA: Lawrence Erlbaum Associates, Inc., Pub. pp.215239.

Khechine, H. \& Lakhal, S. (2018). Technology as a double-edged sword: From behavior prediction with UTAUT to students' outcomes considering personal characteristics. Journal of information technology education: Research, Vol 17, pp. 63-102. Available at https://doi.org/10.28945/4022.

Koehler, M. J., Mishra, P. \& Cain, W. (2013). What Is Technological Pedagogical Content Knowledge (TPACK)? Journal of Education 193(3), p. 13-19

Krathwohl, D.R. (2002). A Revision of Bloom's Taxonomy: An Overview. Theory into Practice, vol 4l(4), pp. 212 - 218

Leeds-Hurwitz, W. (2009). Social construction of reality. In S. W. Littlejohn and K. A. Foss (Eds), Encyclopedia of communication theory. London: Sage, pp. 892-895.

Liu, A. (2012). An exploratory study on application of multimedia technology in college English teaching and learning. Physics Procedia 24 (2012), p. 2334-2338.

Liu, C. \& Tsai, C. (2008). An analysis of peer interaction patterns as discoursed by on-line small group problem-solving activity. Computer and Education, 50 (3), 627-639.

Ministry of Education [MOE], (2013), Information and communication technology in Education, Master Plan 2013-2017. Kathmandu: MOE, GON.

Pacific Policy Research Center [PPRC], (2010). $21^{\text {st }}$ century skills for students and teachers. Honolulu: Research and evaluation division.

Patton, M. Q. (2002). Qualitative research and evaluation methods. London: Sage

Persico, D. \& Pozzi, F. (2011). Tasks, teams and time: Three Ts to structure CSCL process. In F. Pozzi and D. Donatella (Eds.), Techniques for fostering collaboration in online learning communities: Theoretical and practical perspectives (pp. 1-14), NewYork: Information Science Reference.

Phielix, C., Prins, F. J., Kirschner, P. A., Erkens, G., and Jaspers, J. (2011). Group awareness of social and cognitive performance in CSCL environment: Effects of a peer feedback and reflection tool. Computers in human behavior, 27 (3) pp. 1087-1102. 
Pim, C. (2013). Emerging technologies, emerging minds: digital innovations within the primary sector. In G. Motteram (Ed), Innovations in learning technology for English language teaching (p. 15-42). London: British Council

Rank, T., Warren, C., \& Millum, T. (2011). Teaching English using ICT. New York: Continuum International Publishing.

Saunders, B., Kitzinger, J. \& Kitzinger, C. (2015). Anonymising interview data: Challenges and compromise in practice. Qualitative Research Vol. 15(5) pp. 616-632 DOI: 10.1177/1468794114550439

Siraj-Blatchford, I. \& Siraj-Blatchford, J (2006). A guide to developing the ict curriculum for early childhood education. London: Trentham Books Ltd.

Stahl, G., Koschmann, T., \& Suthers, D. (2006). Computer-supported collaborative learning: An historical perspective. In R. K. Sawyer (Ed.), Cambridge handbook of the learning sciences (pp. 409-426). Cambridge: CUP.

Tanujaya, B., Mumu, J. \& Margono, G. (2017). The Relationship between Higher Order Thinking Skills and Academic Performance of Student in Mathematics Instruction. International Education Studies 10 (11), pp. 78-85

UNESCO, (2015). Supporting competency-based teacher-training reformsto facilitate ICT-pedagogy integration,Nepal implementation, Progress report. Kathmandu: Education unit UNESCO

Vygotsky, L. S. (1978). Mind in society: The development of higher psychological process. Cambridge: Harvard University Press.

Weinberger, A. (2011). Principles of transactive computer-supported collaboration scripts. Nordic Journal of Digital Literacy, 6(3), 189202.

\section{Author Bio}

AMBIKA PRASAD POUDEL is a lecturer of English education, and a member of research management cell at Tribhuvan University, Dhankuta Multiple Campus, Dhankuta, Nepal. He has been teaching graduate and master degree students for more than two decades. His main areas of interests are ICTs in education, distance and e-learning, and English language teaching and learning. He has published many articles related to the issues of integration of ICTs in English language education in a variety of journals, and he has been participating and presenting his research papers at different national and international conferences and seminars. Currently, he is a Ph D scholar at Tribhuvan University, Faculty of Education. He also worked as a guest researcher at Oslo Metropolitan University, Oslo, Norway for a year during his $\mathrm{Ph} \mathrm{D}$ exchange stay. 